\title{
Does Mobile Phone Radiation Affect Sperm Quality?
}

\author{
Hanom H. Syam, Jusuf S. Effendi, Tita H. Madjid, Tono Djuwantono, Wiryawan Permadi, \\ Bayu Irsyad
}

Department of Obstetrics and Gynecology, Faculty of Medicine, Universitas Padjadjaran, Dr. Hasan Sadikin General Hospital, Bandung, Indonesia

Email: hanomsyam@gmail.com

How to cite this paper: Syam, H.H., Effendi, J.S., Madjid, T.H., Djuwantono, T., Permadi, W. and Irsyad, B. (2017) Does Mobile Phone Radiation Affect Sperm Quality? Open Access Library Journal, 4: e3711.

https://doi.org/10.4236/oalib.1103711

Received: June 5, 2017

Accepted: June 19, 2017

Published: June 22, 2017

Copyright $\odot 2017$ by authors and Open Access Library Inc.

This work is licensed under the Creative Commons Attribution International License (CC BY 4.0).

http://creativecommons.org/licenses/by/4.0/ (c) (i) Open Access

\begin{abstract}
Background: Male infertility represents almost half of all infertility cases worldwide. High social activities have made some men use earphones or hands-free devices to stay in touch while on the move; hence, often giving radiation exposure to male reproductive organs when their mobile phone is kept in trousers' pocket or on the belt. Because testis is an organ that is susceptible to radiation, the effect of radiation on testis is worth investigating. Objective: This study aimed to determine the direct effect of radiation exposure on the motility quality and viability of human sperm. Material and method: Thirty two healthy men came to donate their sperm. Each sample was prepared by swim-up method. The sperm samples obtained were multiplied by means of dividing each sample into two parts and each part was assigned into the treatment group (exposed to mobile phone radiation) and control group. The sperm sample then underwent a procedure to assess its mobility and viability, which was performed every 30 minutes for 3 hours. Results: A total of 64 washed samples were included in this study. The duration of exposure of mobile phones to sperm at 30,60,90,120,150, and 180 minute did not show significant differences in motility or viability of the sperm compared to those of the control group. Conclusion: This study concludes that the exposure to mobile phone radiation to sperm that has been washed for 3 hours does not lead to a negative effect on motility and viability when compared to the control group.
\end{abstract}

\section{Subject Areas \\ Gynecology \& Obstetrics}

\section{Keywords}

Phone Radiation, Sperm, Motility, Viability 


\section{Introduction}

In today's modern era, it is common to see men, especially those who are socially active, use mobile phones in almost every activity and continuously in years. The use of mobile phone has been increasing globally with time. However, exposure to radiation generated by mobile phones may form oxidative stress that influences the human body [1]. Cell phones emit electromagnetic radiation (EMR), a low radiofrequency (RF) signal with a frequency between 800 and 2200 $\mathrm{MHz}$ [2].

Several studies have concluded that radiation at low frequencies, one of which is caused by a cell phone, is rarely dangerous [3]. On the other hand, there are also studies stating that RF signals resulting from the use of mobile phones (800 - $2000 \mathrm{MHz}$ ) adversely affect the expression of genes and proteins [4] [5]. Specific absorption rate (SAR) is a rate that measures the level of energy absorbed by the human body after an exposure to radiofrequency waves-electromagnetic field (RF-EMF). Specific absorption rate represents the absorption of energy per unit mass of tissue, which is measured in terms of watt per kilogram $(\mathrm{W} / \mathrm{kg})$. Specific absorption rate level of mobile phones varies from 0.12 to $1.6 \mathrm{w} / \mathrm{kg}$ body weight depending on the model. Specific absorption rate level is different when a mobile phone is used in talking, listening, and standby modes (talking > listening > standby) [6]. Moreover, in today's world, the contribution of RFEMF in talking and standby mode increases every year along with the development of mobile phone technology that is "getting smart" in the form of an auto-update feature. This technology has exposed mobile phone users to almost constant radiation even if they do not use the phone all the time. Some evidence on the potential danger has been reported, which is presented as warm feeling up to a burning sensation around the ear [7], headache, decreased immune system [8], and others. Testis is one of the organs in the human body that is sensitive to radiation, even at low doses, in which the radiation may disturb spermatogenesis [9].

Disturbance of spermatogenesis may cause infertility in men. Infertility generally occurs in $15 \%$ of couples in reproductive age, and nearly half of them are caused by male infertility factor [10]. In general, male infertility is caused by the lack of semen, poor sperm quality, or both. In addition to internal causes from such as genetic abnormalities and congenital abnormalities, there are also external causes of male infertility. The external factors relate to lifestyle, pollution, chemicals from food or drugs, lack of nutrients in the body, stress, or working in a sitting position for a long time [11].

One of the causes discussed in this study is lifestyle. In the study of Kilgallon et al. it is revealed that men who keep their mobile phone near the testicles can experience reduced sperm quality [12]. Another study conducted on 371 healthy men presents two factors as the causes of decreased sperm quality. The first is the use of mobile phone that exposes the head with the mobile phone signal transmission. This may lead to infertility due to the fact that electromagnetic radiation from the mobile phone will affect the testes by changing the level of 
hormones produced by the glands located in the head. The second cause is that the electromagnetic radiation from mobile phones can directly cause DNA damage in the male genital tract cells [13]. Men are susceptible to decreased sperm quality due to mobile phone use because men often put their cell phone in their trousers' pocket when they do their daily activities.

In addition to the above studies, there are also studies that present no significant results regarding the effect of mobile phone radiation on sperm quality. Differences in the type of mobile phones, transmission mode in radiation exposure (talking or standby mode) and also the distance between the sperm and the phone can give ambiguous results in these studies [14].

The purpose of this study was to assess the effect of mobile phone radiation on human sperm quality. In this study, sperm exposed to radiation from mobile phones in talking mode (mobile phone turned on during phone calls) was compared to sperm without radiation exposure. This study referred to the habit of men who tend to put the mobile phone in the trousers' pocket or belt and also the habit of using communication accesories (handsfree device), both wire and wireless, while still put the mobile phone in the trousers' pocket or belt.

\section{Methods}

A total of 32 healthy sperm donors came to the Aster fertility clinic of Dr. Hasan Sadikin General Hospital, Bandung as volunteers for this study during May 2017. The semen samples used were selected based on the inclusion criteria, all participants were informed and had signed an informed consent for their participation in the study. The inclusion criteria were all normozoospermia samples obtained by masturbation on the same day as the study, participants already informed to reduce exposure to mobile phone radiation in the pelvic area before sampling, and have been abstinence for 3 - 5 days before sampling [15]. The exclusion criteria were azoospermia and oligozoospermia semen samples, unhealthy donors, and recent sexual intercourse. All sperm donors were pre-selected to meet the inclusion and exclusion criteria in this study. This study was approved by the hospital ethics committee.

Semen samples were obtained through masturbation. Thirty two sperm samples were collected and were doubled by means of dividing each sperm samples into two to be assigned in the treatment group $(n=32)$ and control group $(\mathrm{n}=32)$. The variables examined in both groups were motility and viability. The minimal sample needed is 15 with $80 \%$ power test.

Sperm preparation method applied was the swim-up method by using a $5 \mathrm{cc}$ syringe filled with $1 \mathrm{cc}$ of VITECH and $1 \mathrm{cc}$ of sperm, thus layers were performed (medium at the upper layer and sperm at the bottom layer). This was then incubated at room temperature for 1 hour, while tilted $45^{\circ}$. After an hour, the needle on the syringe was removed and the sperm in the lower part was discarded which left $0.5 \mathrm{cc}$ of top layer. This amount was the sperm yield, which was then immediately examined for its motility as motility in minute 0 . Group A which consisted of prepared sperm sampled was placed around an active mobile 
phone in speaking mode $(\mathrm{n}=32)$ with a distance of $\pm 10 \mathrm{~cm}$. Group B which consisted of prepared sperm sample did not receive any treatment with no active active mobile phone around. All groups were checked for motility and viability every 30 minutes. This checks were performed up to 6 times ( 3 hours). This study only monitored the exposure within 3 hours with the assumption that the maximum use of mobile phone per usage is 3 hours among men.

The results were processed using a table form by calculating the change of motility and viability every 30 minutes. Data were analyzed using Microsoft Excel and SPSS. The p value $<0.05$ was considered statistically significant.

Sperm motility analyzed using WHO simple method, to see the progresive, non progresive, and nonmotile sperm. Viability was analyzed using Trypan blue exclusion test. Trypan blue $0.4 \%$ stains dead cells blue but does not permeate the membrane of living cells, which remain unstained.

\section{Results}

Thirty two sperm samples were collected in this study, which were then doubled by dividing each sample into two and assigned one sample in the treatment group $(n=32)$ and the other in the no treatment group $(n=32)$. The characteristics of sperm donor participants based on their habitual risk factors that may affect sperm such as age, body mass index, caffeine consumption, smoking habits, wearing tight clothing habits, and remaining sauna users were listed in Table 1.

In Table 2 the comparison of sperm motility quality between treatment and control group was discussed. This comparison between the two groups was perfromed every 30 minutes from minute 0 to minute 180 . Every 30 minutes, a significance test of motility quality between treatment and control group was performed. Analysis was conducted using Mann Whitney Test with Bonferroni Correction, showing an overall $\mathrm{P}>0.05$. This means that, statistically, there was no correlation in the motility quality of sperm in minute $0,30,60,90,120,150$, and 180 between the sperm in the treatment and control groups.

In Table 3, data on of sperm viability comparison between treatment and control groups were presented. With Bonferroni post hoc analysis and general linear model test, it was revealed that $p=0.959$, meaning that there was no

Table 1. Patients' Characteristics based on Risk Factors to Sperm.

\begin{tabular}{cc}
\hline Characteristics & Results \\
\hline Age & $28(19-35)$ \\
Body mass index $\left(\mathrm{kg} / \mathrm{m}^{2}\right)$ & $24(21-28)$ \\
Caffeine consumption & $10(31.25 \%)$ \\
Active smoker (n) & $3(9.37 \%)$ \\
Habit of wearing tight clothes & $4(12.50 \%)$ \\
Sauna user $(\mathrm{n})$ & $1(3.12 \%)$
\end{tabular}


Table 2. Comparison of Sperm Motility Quality between Treatment and Control Group.

\begin{tabular}{cccccc}
\hline \multirow{2}{*}{ Motility } & \multicolumn{2}{c}{ Treatment } & \multicolumn{5}{c}{ Control } & \\
\cline { 2 - 5 } & $\begin{array}{c}\text { Median } \\
(\text { min-max })\end{array}$ & Mean rank & $\begin{array}{c}\text { Median } \\
(\text { min-max })\end{array}$ & Mean rank & \\
\hline Minute 0 (\%) & $80(70-92)$ & 31.89 & $81(69-92)$ & 33.11 & 1.000 \\
Minute 30 (\%) & $73.5(43-86)$ & 32.27 & $72(55-90)$ & 32.73 & 1.000 \\
Minute 60 (\%) & $70(47-86)$ & 29.91 & $72.5(58-96)$ & 35.09 & 0.884 \\
Minute 90 (\%) & $70(47-86)$ & 29.91 & $72.5(58-96)$ & 35.09 & 0.884 \\
Minute 120 (\%) & $60(24-79)$ & 29.58 & $62.5(50-76)$ & 35.42 & 0.805 \\
Minute 150 (\%) & $61(46-75)$ & 32.19 & $56.5(47-84)$ & 32.81 & 1.000 \\
Minute 180 (\%) & $66(44-75)$ & 32.05 & $64(49-79)$ & 32.95 & 1.000 \\
\hline
\end{tabular}

Table 3. Differences in Sperm Viability Quality between Treatment and Control Groups.

\begin{tabular}{ccccc}
\hline Viability & $\begin{array}{c}\text { Treatment }(\mathrm{n}=32) \\
\text { Mean } \pm \text { SD }\end{array}$ & $\begin{array}{c}\text { Control }(\mathrm{n}=32) \\
\text { Mean } \pm \text { SD }\end{array}$ & Mean Difference (CI 95\%) & P value \\
\hline Minute 0 (\%) & $81.50 \pm 3.04$ & $82.28 \pm 2.37$ & $-0.781(-2.14-0.58)$ & 0.256 \\
Minute 30 (\%) & $80.56 \pm 2.85$ & $81.25 \pm 1.97$ & $-0.688(-1.91-0.54)$ & 0.266 \\
Minute 60 (\%) & $79.91 \pm 3.03$ & $80.34 \pm 1.72$ & $-0.438(-1.67-0.79)$ & 0.480 \\
Minute 90 (\%) & $78.69 \pm 3.12$ & $79.28 \pm 1.76$ & $-0.594(-1.86-0.67)$ & 0.352 \\
Minute 120 (\%) & $78.00 \pm 3.06$ & $78.44 \pm 1.98$ & $-0.438(-1.73-0.85)$ & 0.500 \\
Minute 150 (\%) & $77.19 \pm 3.24$ & $77.47 \pm 2.60$ & $-0.281(-1.75-1.19)$ & 0.703 \\
Minute 180 (\%) & $76.06 \pm 3.04$ & $76.41 \pm 3.14$ & $-0.344(-1.89-1.20)$ & 0.658 \\
\hline
\end{tabular}

significant statistical different in the viability quality in minute $0,30,60,90,120$, 150 , and 180 between the treatment and control groups.

Figure 1 also shows the observation of sperm viability quality every 30 minutes for 3 hours by investigating whether there was a difference between the sperm viability quality with radiation exposure for 3 hours and the viability quality of untreated sperm. As mentioned above, there was no significant difference found for each 30 minutes observation for 3 hours that it was concluded that phone radiation for 3 hours did not affect the viability quality of sperm. Some previous studies also support the findings of this study.

\section{Discussion}

This study shows that even though the treatment group received radiation from a mobile phone in talking mode (during phone calls), there is no difference is found in the motility quality of sperm when compared to the control group. A different results have been stated by several previous studies which retrospectively found disturbing effect of mobile phone radiation on the spermatozoa motility characteristics. A retrospective study on 304 men has presented a significant reduction in the percentage of sperm with progressive motility in the group that received mobile phone treatment. In that study, almost $65.7 \%$ 


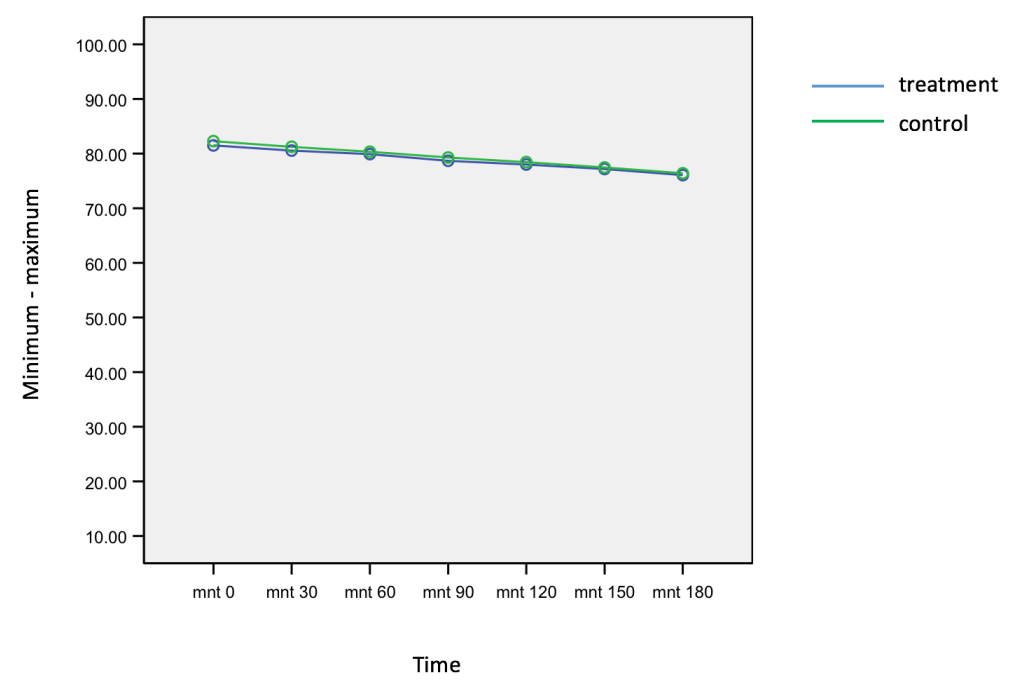

Figure 1. Time chart of radiation measurement against sperm viability quality.

of patients who did not use mobile phone has a normal motility compared to only $17 \%$ among patients who frequently use mobile phone [16]. Furthermore, another retrospective study also stated that the duration of mobile phone use and daily transmission also create negative effect on motility [13]. This study proves that there is no effect found on the sperm motility quality when the sperm group was treated with 3 hours of radiation.

In the present study, the sperm was exposed with mobile phone radiation for 3 hours. This duration of exposure was selected because this study aimed to assess the effect of mobile phone radiation on human sperm quality in daily use of mobile phone, which assumes that the normal daily use of mobile phone is not more than 3 hours per use.

Other studies also discuss the length of exposure to mobile phone radiation per day. Davoudi et al. found a reduction in the rapid progressive motility proporsion from $32.3 \%$ to $26.1 \%$ after using mobile phone for 6 hours a day for 1 month [17]. The use of mobile phone of 4 or more hours a day has produced a significant reduction in motility, viability, and morphology of the sperm [1].

An animal study by Dasdag et al. on rats that were exposed to mobile phone for 20 minutes a day for 1 month with a distance of $0.5 \mathrm{~cm}$ has produced insignificant result and that there is no proof of the side effects on the histology of testes, immune re-activation of p53, number of sperm, morphology of sperm, malondialdehyde concentration, and diameter of testical seminifrous tubule [18].

Hamada et al. stated that there is no conclusion that can be drawn regarding the mobile phone RF-EMW radiation effect on human body and male reproductive tract as long as there is no study protocol that takes into account an adequate control group and limiting external variations [14]. The effect of exposure duration has been found in a study by Salama et al. that used adult rabbit subjects that were exposed to the mobile phone for 8 hours a day for 12 
weeks. In that study, the sperm motility is at the same level as control up to week 10 which was followed by a significant reduction in the group that was exposed to radiation compared to the control group [19].

Several studies that show a negative effect of radiation on sperm viability present the negative effect on the sperm motility. A study performed by Wang et al. [20], concludes a viability reduction along with sperm motility reduction when exposed to radiation. The same is true in a metaanalysis study performed by Adams et al. [21] on 5 studies which shows a reduction of viability of sperm exposed by radiation that is accompanied with sperm motility reduction [2] [22] [23].

Ambiguity still persists in studies regarding mobile phone with controversial findings. As already stated, there are a lot of studies that have shown a negative correlation between mobile pone and human body, especially male reproductive organs. However, there are also still studies that conclude the effect of RF-EMW as negligible and that there is no correlation between mobile phone and semen parameters [14]. A study performed on male population in Brazil in 2011 have categorized the subjects according their mobile phone use. Of 571 subjects, there were subjects who did not use mobile phone $(\mathrm{n}=24)$ while others used mobile phone with a daily use of under 120 minutes $(\mathrm{n}=266), 120$ - 240 minutes $(\mathrm{n}=$ $88)$, and more than 240 minutes $(n=120)$. The results show that the motility, viability, normal morphology, and number of sperm are not significantly different among the four groups. Through this study, Feijo et al. suggested that differences in race and other unidentified factors may play a role in creating different impacts of electromagnetic wave on the sperm parameters in different male populations [24].

For future study, it may be necessary to include questions on the demographic background of the participants, such as age, where they live, number of children, occupation, race, and educational status. Questions on medical history and treatment related to fertility (such as varicocele and orchitis), lifestyle (smoking and alcohol consumption) also need to be included. Further question on the mobile phone use every day, such as the number of mobile phones owned and duration of call in a day is also needed. The length of use migh be categorized into several groups (30,60, 90 minutes). Considerations on the use of mobile phone accessories such as handsfree devices or earphones, length of owning the mobile phone, talking while charging, type of mobile phone, and frequency use should be also included.

The limitations of this type of study are the lack of standardized testing protocol, no testing for certain stage of sperm cell development to understand the maturity of cells, and lack of standardized method to prepare and exposed sperm. In terms of the mobile phone itself, the various differences in frequency of radio wave, SAR level of each mobile phone, duration of exposure to sperm cells, type of phone used, transmission mode during operation, and distance between the cells and phone are found. These variations contribute to the ambiguity in the results of studies on the correlation between mobile phone and 
sperm quality [14]. The resistance of sperm against radiation is different for every man with DNA repair system and antioxidant capacity determine the resistance mechanism against EMW radiation.

The Specific Absorption Rate varies in these studies, including the frequency, intensity, polarization, and configuration of radiation source, and body. The results of studies peformed on test animals also need to be interpreted with care due to the differences in the anatomical characteristics, body size, and reproductive organ (such as whether the scrotum is hanging or not). The negative effect of mobile phone radiation on the motility and viability in in vitro studies and its effect to test animals often lead to negative effect in sperm parameters in human study. The communication signal in standby mode does not affect semen parameters significantly. On the contrary, the more frequent use of mobile phone in daily life may disturb the characteristics of spermatozoa motility.

\section{Conclusion}

In this study, no significant negative effect of mobile phone radiation on the motility and viability quality of spem is found. There is a need for further study using a control group that is purely free from mobile phone radiation exposure and bigger sample size to gain clearer information for the male mobile phone users who want to keep up with the current technology advances.

\section{References}

[1] Gorpinchenko, I., Nikitin, O., Banyra, O. and Shulyak, A. (2014) The Influence of Direct Mobile Phone Radiation on Sperm Quality. Central European Journal of Urology, 67, 65-71

[2] Agarwal, A., Deepinder, F., Sharma, R.K., Ranga, G. and Li, J. (2008) Effect of Cell Phone Usage on Semen Analysis in Men Attending Infertility Clinic: An Observational Study. Fertility and Sterility, 89, 124-128.

[3] Erogul, O., Oztas, E., Yildirim, I., Kir, T., Aydur, E., Komesli, G., et al. (2006) Effects of Electromagnetic Radiation from a Cellular Phone on Human Sperm Motility: An in Vitro Study. Archives of Medical Research, 37, 840-843.

[4] Hardell, L. and Sage, C. (2008) Biological Effects from Electromagnetic Field Exposure and Public Exposure Standards. Biomedicine \& Pharmacotherapy, 62, 104-109.

[5] Hyland, G.J. (2000) Physics and Biology of Mobile Telephony. The Lancet, 356, 1833-1836.

[6] Hung, C.S., Anderson, C., Horne, J.A. and McEvoy, P. (2007) Mobile Phone "TalkMode” Signal Delays EEG-Determined Sleep Onset. Neuroscience Letters, 421, 82 86.

[7] Oftedal, G., Wilen, J., Sandstrom, M. and Mild, K.H. (2000) Symptoms Experienced in Connection with Mobile Phone Use. Occupational Medicine, 50, 237-245. https://doi.org/10.1093/occmed/50.4.237

[8] Agarwal, A., Singh, A., Hamada, A. and Kesari, K. (2011) Cell Phones and Male Infertility: A Review of Recent Innovations in Technology and Consequences. International Brazilian Journal of Urology, 37, 432-454. https://doi.org/10.1590/S1677-55382011000400002

[9] Ogilvy-Stuart, A.L. and Shalet, S.M. (1993) Effect of Radiation on the Human Re- 
productive System. Environmental Health Perspectives, 101, 109-116. https://doi.org/10.1289/ehp.93101s2109

[10] Miyamoto, T., Tsujimura, A., Miyagawa, Y., Koh, E., Namiki, M. and Sengoku, K. (2012) Male Infertility and Its Causes in Human. Advances in Urology, 2012, Article ID: 384520. https://doi.org/10.1155/2012/384520

[11] Kumar, N. and Singh, A.K. (2015) Trends of Male Factor Infertility, an Important Cause of Infertility: A Review of Literature. Journal of Human Reproductive Sciences, 8, 191-196. https://doi.org/10.4103/0974-1208.170370

[12] Kilgallon, S.J. and Simmons, L.W. (2005) Image Content Influences Men's Semen Quality. Biology Letters, 1, 253-255. https://doi.org/10.1098/rsbl.2005.0324

[13] Fejes, I., Zavaczki, Z., Szollosi, J., Koloszar, S., Daru, J., Kovacs, L., et al. (2005) Is There a Relationship between Cell Phone Use and Semen Quality? Archives of Andrology, 51, 385-393. https://doi.org/10.1080/014850190924520

[14] Hamada, A.J., Singh, A. and Agarwal, A. (2011) Cell Phones and Their Impact on Male Fertility: Fact or Fiction. The Open Reproductive Science Journal, 5, 125-137.

[15] Lu, J.C., Huang, Y.F. and Lu, N.Q. (2010) WHO Laboratory Manual for the Examination and Processing of Human Semen: Its Applicability to Andrology Laboratories in China. National Journal of Andrology, 16, 867-871.

[16] Wdowiak, A., Wdowiak, L. and Wiktor, H. (2007) Evaluation of the Effect of Using Mobile Phones on Male Fertility. Annals of Agricultural and Environmental Medicine, 14, 169-172.

[17] Davoudi, M., Brossner, C. and Kuber, W. (2002) The Influence of Electromagnetic Waves on Sperm Motility. International Urogynecology Journal, 19, 18-32.

[18] Dasdag, S., Zulkuf, A.M., Aksen, F., Yilmaz, F., Bashan, M., Mutlu Dasdag, M., et al. (2003) Whole Body Exposure of Rats to Microwaves Emitted from a Cell Phone Does Not Affect the Testes. Bioelectromagnetics, 24, 182-188. https://doi.org/10.1002/bem.10083

[19] Salama, N., Kishimoto, T. and Kanayama, H.O. (2010) Effects of Exposure to a Mobile Phone on Testicular Function and Structure in Adult Rabbit. International Journal of Andrology, 33, 88-94. https://doi.org/10.1111/j.1365-2605.2008.00940.x

[20] Wang, D., Li, B., Liu, Y., Ma, Y.F., Chen, S.Q., Sun, H.J., et al. (2015) Impact of Mobile Phone Radiation on the Quality and DNA Methylation of Human Sperm in $\mathrm{Vi}^{-}$ tro. National Journal of Andrology, 21, 515-520.

[21] Adams, J.A., Galloway, T.S., Mondal, D., Esteves, S.C. and Mathews, F. (2014) Effect of Mobile Telephones on Sperm Quality: A Systematic Review and Meta-Analysis. Environment International, 70, 106-112.

[22] De Iuliis, G.N., Newey, R.J., King, B.V. and Aitken, R.J. (2009) Mobile Phone Radiation Induces Reactive Oxygen Species Production and DNA Damage in Human Spermatozoa in Vitro. PLoS ONE, 4, e6446. https://doi.org/10.1371/journal.pone.0006446

[23] Agarwal, A., Desai, N.R., Makker, K., Varghese, A., Mouradi, R., Sabanegh, E., et al. (2009) Effects of Radiofrequency Electromagnetic Waves (RF-EMW) from Cellular Phones on Human Ejaculated Semen: An in Vitro Pilot Study. Fertility and Sterility, 92, 1318-1325.

[24] Feijo, C., Junior, S.V. and Esteves, S.C. (2011) Lack of Evidence That Radiofrequency Electromagnetic Waves (RF-EMW) Emitted by Cellular Phones Impact Semen Parameters of Brazilian Men. Human Reproduction, 26, i139-i140. 
Submit or recommend next manuscript to OALib Journal and we will provide best service for you:

- Publication frequency: Monthly

- 9 subject areas of science, technology and medicine

- Fair and rigorous peer-review system

- Fast publication process

- Article promotion in various social networking sites (LinkedIn, Facebook, Twitter, etc.)

- Maximum dissemination of your research work

Submit Your Paper Online: Click Here to Submit

Or Contact service@oalib.com 